\title{
"The Others":
}

\section{Sex Offenders' Social Identities in Probation Approved Premises}

\section{Introduction}

The ways in which offenders experience and engage in the process of community reintegration and resettlement after imprisonment has become a significant growth area of criminological study over the last decade. As illustrated in Maruna's (2001) influential work on the personal and emotional journeys that offenders traverse, agencies undertaking this work must engage with offenders in the construction of positive self and social identities which enable the offender to become an 'ex-offender'. This implies that offenders' understandings and experiences of reintegration and resettlement work need to be explored in order to appreciate the complexity and depth of these factors which may affect their identity constructions. However, investigations into how sex offenders experience criminal justice and probation work are limited and often fail to engage with sex offenders as active agents (c.f. [references to insert after anonymous review]; Laws and Ward, 2011; Wincup, 2003). Ost (2009) suggests this is because of the moral condemnation of sex offending, which inhibits critical research and especially that which requires sex offenders to express themselves, their opinions and experiences.

The majority of research which has considered the experiences and responses of sex offenders in rehabilitation and resettlement work has tended to focus on the "artificial world" (Hudson, 2005: 147) of formal treatment groups. This work has emphasised the role of sex offender groups as significant in the challenging or formation of offender identity constructions, although with varying conclusions. For example, Hudson (2005) observed that members of a sex offender group positively supported each other to engage in offence-based 
cognitive behavioural work, whilst Lacombe (2008) argued that the same type of treatment work coerced sex offenders into accepting negative personal identities as dangerous offenders. It may be that the culture of such treatment groups and the attitudes of facilitators towards sex offenders is a decisive factor is determining the success of such programmes. Collins and Nee (2010) found that prison therapists held negative views on sex offenders' ability to change that centred on their inability to divorce the individual from the offence, which undermined their treatment efforts. However, these studies focussed on formal (and mandatory) treatment programmes and so did not explore in detail the importance of informal social structures and relationships. The significance of these to sex offender desistance from offending and risk management on release from prison is indicated by pro-social modelling work undertaken by probation officers, which emphasises the need to promote positive social relationships in order to effect positive behavioural and attitudinal change (a strategy through which probation officers model appropriate, respectful social relationships and behaviour when dealing with offenders) (National Probation Directorate, 2005).

The issues noted above indicate that sex offender reintegration and resettlement work is predicated on supporting individuals to construct themselves as both ex-offender and non-sex offender, but that the broader cultural ways of thinking about sex offenders, as well as criminal justice work which engages with them as a group of sex offenders, may undermine this. In order to explore these issues this paper reports on an in-depth ethnographic study of a Probation Approved Premises (referred to in this paper by their moniker: hostel), which explored the informal social structures of hostel life and considered how they may relate to sex offenders' active engagement in, and experience of, reintegration and resettlement work. Probation hostels are used in England and Wales as part of the release process for high risk offenders, including sex offenders, as a temporary semi-secure residence during the transition 
between release from prison and resettlement in the community: a period characterised as "a traumatic, overwhelming experience." for offenders (Kenemore and Roldan, 2006: 14). Despite the importance of probation hostels to this critical phase in managing high risk offenders, there is little academic work considering them (c.f. [references to insert after anonymous review]; Wincup, 2003). This article begins with an overview of the work undertaken with sex offenders in hostels in order to contextualise the study and to explore the cultural discourses underpinning practice. These observations are used to analyse the nature of the social experiences of sex offenders found in this study and the implications this has for future policy and practice.

\section{Probation Approved Premises and Work with Sex Offenders}

In England and Wales there are currently 104 Probation Approved Premises accommodating approximately 2500 inmates assessed as at high risk of reoffending, causing serious harm and/or absconding on bail or licence conditions (NAPO, 2011). Over half of hostel residents are charged (and on bail with residence requirement) or convicted of a sexual offence (NAPO, 2011) with admission based on an assessment of the risk of harm posed by offenders; priority being given to those considered to be high or very high risk (Hansard, 2004; NAPO and NPS, 2009). The pressure on the capacity of the hostel estate to manage sex offenders has increased since public and media concern surrounding sex offender accommodation in 2004 caused some hostels to refuse to accommodate sex offenders on the grounds that they are sited too near to areas which children or vulnerable people may frequent (primarily schools) (Hansard, 2004).

The most recent probation national strategy said little about the purpose of hostels other than to emphasise their role within the offender management model in terms of implementing risk 
management plans (Ministry of Justice, 2007). However, a thematic inspection of Probation Approved Premises (HMI Probation et al. 2008), echoed by the Approved Premises Handbook (NAPO and NPS, 2009), outlined the official role of hostels as supporting public protection work through effective offender management, including enhanced supervision and a residential monitoring and life-skills regime. In particular, the report concluded:

"There was convincing evidence that approved hostels were better equipped to manage the risks posed by sex offenders in the community than other community-based arrangements." (HMI Probation, 1998: 72).

However, the concern that hostel accommodation may not always be appropriate for high risk sex offenders was acknowledged by the National Probation Service (NPS, 2004), especially in respect to the possible negative effects of accommodating high risk sex offenders in a communal space that may facilitate social networking by sex offenders whilst inhibiting social integration and, in consequence, extend institutionalisation and social isolation (c.f. Atkinson et al., 2005; Baldry et al., 2002; NPS, 2004; Scottish Executive, 2003).

These policies, inspections and concerns about hostel practice with sex offenders indicate that they are routinely conceptualised as something rather different to the 'normal' criminal (Hudson, 2005). In general, recent probation work with offenders, particularly in terms of desistance from offending and reintegration, has tended to emphasise offenders' cognitive, behavioural and social deficits, and the interventions or support that they need to be reintegrated as 'normal', reaffirmed social citizens. This conceptualisation accords with Young's (1999 and 2007) exploration of 'liberal othering', in which offenders are understood in terms of "essentialist notions of identity" (Young, 2007: 4), whereby categories of offenders are increasingly based on distinctions of difference. However, policy discourses have emphasised sex offenders in popular punitivist terms of the 'dangerous other', from 
whom society needs protecting (Hudson, 2005): thus defining sex offenders in terms of group characteristics but also as distinct, separate and different from other people, including other offenders. Hence, additional and different policies from other offenders have been implemented, as evidenced by previously unprecedented measures in modern criminal justice practice, including extended sentencing, registration, disclosure, notification, and multiagency public protection (although many of these have subsequently been expanded to work with other offender groups). This conceptualisation of sex offenders accords less with 'liberal othering' and more with "conservative demonization" (Young, 2007: 5): whereby society, media, communities or individuals project on to the object of demonization negative attributes and an understanding of the individuals as essentially different and incapable of changing so as to accord with concepts of normality (Laws and Ward, 2011).

However, some areas of criminal justice work are predicated on the belief that sex offenders are socially redeemable, as evidenced in work to facilitate sex offender cognitive and behavioural change in Sex Offender Treatment and Group Programmes (SOTP and SOGP) and the Good Lives Model (Ward et al., 2006), as well as to support social reintegration through Circles of Support and Accountability (COSA) ${ }^{\mathrm{i}}$ (Hanvey et al., 2011; Laws and Ward, 2011). The latter, in particular, has developed as a constructive, person-centred, holistic approach to high risk sex offender social reintegration and risk management, which emphasises the offender's ability to construct positive personal and social identities through the rejection of the sex offender label (Hanvey et al. 2011). A network of local community volunteers supports the core member (sex offender) in this process by engaging them in prosocial activities, whilst holding them accountable for their decisions and actions. However, this approach is juxtaposed with the underpinning essentialist assumption that they (the sex offender), and others, need to be ever vigilant as to their risk factors and continually monitor 
their cognitions and behaviours to prevent future manifestations of their inherent difference (reoffending). It is, thus, suggested that the discourses underlying probation practice and policy, as well as those structuring sex offender social relationships, need to be uncovered and considered in light of the potential social exclusionary effects.

\section{The Study}

This paper reports on a twenty-one month ethnographic case study of a probation hostel, focussing on the detail of day-to-day experiences of living in semi-secure hostel accommodation for people charged or convicted of sexual offences. The Probation Approved Premises studied was chosen as it was the main hostel in the area (within which the author worked) to accommodate sex offenders; only one other admitted sex offenders at all. This site became the case study due to the support of the hostel management team for the research and their help in negotiating access with the (multi-agency public protection panel)MAPPP and (multi-agency risk assessment committee) MARAC ${ }^{\mathrm{ii}}$ chair and Probation Area management team. Situated on the edge of a small city, the hostel was similar in size, location and conditions to others of this nature and resident population, and so was able to be used as an example of semi-secure institutional accommodation for charged or convicted sexual offenders. The hostel and the Probation Area are unnamed in accordance with the terms of access agreed. For further information on the process of fieldwork please see [reference to be inserted after anonymous review].

The fieldwork coupled in-depth interviews with staff and residents (including sex offenders and non-sex offenders) with direct observations of hostel life and twelve MARAC meetings (see [reference to insert after anonymous review]). This method enabled the author to engage with residents and staff within the hostel; observing them within their own social 
environment and understanding their experiences from the unique, subjective perspective of the research participants (Ferrell, 1998: Fetterman, 1998). This paper draws predominantly on the interview and observation work in the hostel (see [reference to insert after anonymous review] for more details on the research approach and fieldwork relationships of the researcher).

The first phase of the fieldwork combined direct observation of hostel life, operation and practices with unstructured and spontaneous conversations with residents and staff. This exploratory work enabled the themes for exploration in the following phases to be developed through a grounded theory approach by identifying the areas of importance for residents and staff living within the hostel. The themes included: social and personal relationships between residents and with staff; experiences of transitioning into and out of the hostel; attitudes towards hostel accommodation, offence-based interventions, personal risk management and move-on plans. Through these themes the social interactions between individuals and social groups as well as their relationship with the hostel as an institution of change become central foci of study. Fifty-seven observation periods were undertaken at all times of the day (including during the night) and all days of the week. As activities varied considerably according to curfew times, weekends and working hours this enabled a full picture of life in the hostel to be explored. In addition, the long time period over which the fieldwork was conducted enabled the researcher to observe changes in hostel policy and practice as well as the influencing dynamics of individual residents (only one resident was accommodated in the hostel throughout the fieldwork period).

The early themes which emerged from the observation work informed the conduct of the formal semi-structured interviews. Forty-one interviews were completed with residents (24: 
23 male and 1 female) and staff (17: 15 male and 2 female). All staff and residents were given opportunities for interview. These ratios are reflective of those in the hostel as a whole. Of the staff, most who took part in interviews were residential services officers (RSO: not probation trained and undertook daily front-line duties in the hostel): $8 \mathrm{RSO}, 3$ relief RSO, 5 probation services officers (PSO) and 1 senior probation officer. Of the residents, because of the focus on sex offenders, 21 of the respondents were convicted or charged with sexual offences, which is a slight over-representation of the sex offender population. Many more staff and residents were involved in the observation phase of the work and readily engaged in informal conversations about the research topic. All residents and staff were informed that they could request to not be referred to in the research report. No one requested this, withdrew from the interviews or declined an interview when approached. The interview schedules for both residents and staff explored the same areas, but from the unique perspective of their respective positions in the hostel. Topics discussed followed the themes identified in phase one: hostel aims and purpose; life in a hostel (including residents' social relationships and working cultures); relationships between staff and residents; attitudes towards the work of the hostel and offence-based interventions; future planning (including risk management and community reintegration). Interviews, though structured around these themes, were primarily led by the interviewee and so were responsive to their individual situation, concerns and experiences. For further information on the methodology and design of the project, please see [reference to insert after anonymous review].

In writing the field notes, all participants, local areas and the hostel were anonymised and ascribed code names. In this paper the code names of participants have been changed to pseudonyms. 


\section{Findings: the social experience of hostel life for sex offenders}

This study found that residents' social life was clearly structured into social groupings which were the foundation of residents' social identities. These groups were predominantly static in nature, although membership varied in response to changing resident populations and subsequent changing relationships within the hostel. Membership of these social groups shaped and coloured life for residents whilst accommodated in the hostel. Although limited and now rather dated, previous work on informal social grouping within criminal justice institutional settings has characterised this as "the core of every day and residential centre and all that happens there." (Brown and Clough, 1989: 4).

The following discussions explore and exemplify the ways in which residents and staff in the hostel understood and constructed the groups in terms of dualities: one group being the opposite of another. As expected, these groups formed around differences in offence primarily, but were also affected by social demographic categories, with age being the main such latter division observed (although the small numbers of residents accommodated at any one time may have reduced the number of social divisions possible).

Both [Graham and Paul, an older and younger resident respectively, both convicted of child sexual abuse offences] do not like it in the hostel because of the mix of people, for example, the older ones with the younger ones, drug addicts with non-drug addicts. It causes tensions [....] (1.4 field notes)

Here the residents discussed offence categories in terms of drug addicts and non-drug addicts, However, the distinction between the two main groupings within the hostel formed around the categories of sex offender and non-sex offender whereby the category 'drug addict' referred to a resident grouping comprising of non-sex offenders. Although the majority of this 
group did have drug addictions or convictions for drug offences this was not uniformly the case and members had a wide range of offence histories from drug smuggling, dealing and possession to burglary, fraud, murder and other violent offences. The category of 'sex offender' referred to a resident grouping comprising of anyone convicted or charged with offences linked to contact, non-contact and child or adult sexual offences.

But you still get the same groups forming [as in prison]. Those on drugs and the others. You know what I mean. (Jim in interview with Pete, both older residents convicted of sexual offences against children).

Members of the drug addict (non-sex offender) group always referred to the group divisions in terms of themselves as 'other' to the sex offender group. However, members of the sex offender group referred to themselves as 'other' to the drug addict group in public, but to the drug addict (the non sex offender) group as 'other' to themselves (as the sex offender group) in private. Thus, the label 'other' was used variously to refer to each of these primary social groupings with sex offender residents using the label 'drug addict' group as a way of masking their own sex offender status. This avoidance and denial of the identity of 'sex offender' has been noted in research on sex offenders in other contexts (c.f. Hudson, 2005). That these labels were embedded in cultural language; used to denote difference amongst the resident group, as well as encapsulating social stigmatic attitudes towards one set of residents, indicates one of the mechanisms by which group structures were maintained.

Within the talk of other (non-sex offender) residents and staff it was evident that the sex offender group were all associated with offending against children:

Alan [relief RSO] regards sex offenders with "contempt and disgust". He refers to them as "those paedophiles" or "those paedos" This includes all sex offenders. (19.9 field notes) 
On occasion this was challenged by those who had offended against adults:

Andrew [convicted of multiple rapes against adult women] was upset because someone called him a 'paedo'. He was sitting with Carl, Ben and Matt [all child sexual abusers] and responded that he was not interested in kids. Later when Sam [convicted of drug related offences] asked him what he was doing tomorrow he said he was "going to sniff glue and then go to the park to watch the kiddies". Sam was shocked and said he shouldn't say such things because of the other three residents there. Andrew said "I don't give a fuck about them", although he spends much of his social time with them. (24.5 - 25.5 field notes).

That Andrew took such exception at being labelled a child sexual abuser illustrates the distinct subgrouping within the larger sex offender group. This desire of adult sexual abusers to ensure that, although they may associate with child sexual abusers, they are not identified with them indicates the hierarchy of grouping within the hostel, and within the sex offender group itself (see also Hudson, 2005). Notably at no time did any child sexual abusers object to being identified as an adult sexual abuser or as a member of the 'drug addict' group, with some residents actively creating alternative offending histories to mask or change their socially perceived identity:

I say I'm here for violence and they believe me, it helps that I do have a temper on me. Then they leave me alone [...]. (Paul in interview, younger resident convicted of sexual offences against children).

The sex offender group cohesion was also affected by the differences in ages of the residents. This was often evident in residents' cultural associations and preferences, for example, "older residents do not like the volume young ones sometimes play their music." (Nick, resident convicted of drug related offences, in his 30s: 4.1. field notes). In this hostel most sex offender residents were over 40 years of age, with the majority of other residents being under 35 years. However, there were three sex offender residents who were in their 20s. The interaction between the older and younger sex offender residents illuminated both the 
significance of age as well as the greater importance of offence category as a grouping distinction:

"That's what makes it so hard for people like Luke [20 year old convicted of child sexual abuse offences], he's in between groups. The drug addicts are about his age, they're much younger really, but his offences are the other group. He doesn't really fit anywhere. (Jim in interview, older resident convicted of child sexual abuse offences).

\section{Discussion: the effects of grouping on and by hostel practice}

This discussion explores the social identities of residents set out above in terms of the structural and cultural mechanisms which support group formation in hostels and the significance this has in terms of offenders' construction of self-identity and probation practice in resettlement and reintegration work.

\section{Structural effects on grouping}

Group bonds form due to a number of influences, perhaps the most powerful of which is proximity. The fact that so many sex offenders were accommodated in a communal living space increases both the likelihood of social bonds forming, and the strength of these bonds. Buunk (1996) and McPherson et al. (2001) both note that people who are in close and frequent contact with each other are more likely to develop friendships (the principle of homophily). Additionally, people who discover that they have shared experiences, values and attitudes are more likely to form strong relationships. That the sex offenders did not form social bonds outside of their group whilst in the hostel (other than pre-existing family contacts) also accords with work on friendship formation. We are more likely to want to spend time with, and take note of, people who are in the same cultural groups and who profess similar views and attitudes as ourselves because it positively reinforces our preexisting ideas and schemata (Buunk, 1996 and Haslam et al. 2005). This effect is supported 
by the limited information flow between social groups as opposed to within a group. This means that members of a group are subject to information (and the bias of information) from other members of a group to a greater extent than from people outside of the group (McPherson et al., 2001). Therefore, once in the group, the group structure limits outside social influence, maintaining and reinforcing the group identity and culture: in this case, that of sex offender.

The effect of proximity was compounded by shared experience, for example, all sex offender residents were required to attend the mandatory Sex Offender Group Programme (SOGP). Sex offender residents frequently noted that their social identity as a 'sex offender' was further constructed in this way as they not only identified with each other but were also placed in a situation where they were compelled to disclose intimate information about themselves; consolidating their sex offender group membership and isolation from other residents, staff and local communities. Lacombe's (2008) critical ethnography of a sex offender treatment programme in Canada uncovered the function of such programmes in persuading sex offenders to internalise the construct of themselves as persons who are incurably dangerous and "consumed by sex" (Lacombe, 2008: 56). The aim of the programme was to make "offenders recognise that their criminal identity as sex offender constitutes the pivot around which all other aspects of their personality revolve" (Lacombe, 2008: 72). Lacombe concluded that the programmes, which have little empirical evidencebase (though this is growing, c.f. Brown, 2005) nor clear evidence of effectiveness, transformed sex offenders into a "new self" (Lacombe, 2008: 72); one that is focussed on perceiving themselves as dangerous, prolific sexual offenders, who have to continually guard themselves against the (high) risk of reoffending. Both informal sex offender groups in the hostel and formal sex offender groups in treatment programmes are suggested to be similar in 
that they both socially isolate and reinforce the sex offender label. This can be juxtaposed with the socially integrative COSA formed from groups of community volunteers around a single sex offender, thus, breaking the sex offender peer networks which characterise the former groups whilst providing alternative, pro-social relationships and influences. COSA, unlike SOGP and other offence-based treatment programmes, are not based on cognitive behavioural therapy (CBT) but rather a group-based programme underpinned by restorative justice principles, which assumes sex offenders can be 'restored' to a position of positive citizen-hood with appropriate emotional and practical support, whilst being held responsible and accountable for their actions (Hanvey et al.,2011). This difference in approach suggests that COSA may be able to support sex offenders who are newly released from prison to reject the sex offender identity, however, that these individuals are (often simultaneously) required to attend SOGP and other CBT programmes which Lacombe (2008) suggests reinforces and internalises the sex offender identity, indicates that these may be discordant competing approaches. The role of sex offender peer networks (and the nature of the group identity) may be critical in providing a mediating lens through which an individual cognitively engages with, or resists, any particular intervention. Thus, understanding the significance and nature of sex offender peer networks in any criminal justice institution is argued to be essential to appreciating and developing mechanisms to manage the range of influences acting upon individuals to construct their self identity and, consequently, their likelihood of reoffending.

\section{Cultural effects on grouping}

The offence categories used by residents and staff to denote social grouping in the hostel were not neutral descriptions, but rather value-laden judgements of the members of the sex offender group, who were constructed as being both different to other people and inferior; not 
only in terms of social status, but also in respect to behaviour, morality, thinking, attitudes, values and sexual desires.

"No one likes them, they [are] seen as beasts." (Joanne, older resident convicted of violent offences, 8.8 field notes)

Othering is a process in which groups of people come to be defined by a 'them' and 'us' categorisation in which that group with greatest social power defines the other group as fundamentally different and separate to themselves (Krumer-Nevo and Benjamin, 2010). This othering process was used by both non-sex offender residents and staff and accorded with Young's (2007) concept of conservative demonization, in that sex offenders were conceived of as essentially different and morally worse than other 'normal' people. Although staff regarded all residents as different and 'other' to themselves, their talk exemplified that nonsex offender residents (the others) were constructed in terms of deficits (liberal othering), whilst talk about sex offender residents demonstrated their othering in terms of demonization:

"They could be branded! No, that would be going too far... (laughs) They could be pervert 1, pervert 2 and pervert 3!" (Alan, relief RSO, 31.7 field notes)

The talk and language of other residents and staff illustrate that condemnation of residents' criminal behaviour became condemnation of the person with the application of the label 'sex offender' being not merely a descriptive category indicating offence type, but short-hand for the socially dominant discourse about sex offenders. The label invokes a ready-made and socially understood narrative about sex offenders (Presser, 2009), which gives coherence and meaning to not only the concept of a sex offender but also to their personal and social identity. That this label (and the associated narrative) may be internalised as residents' master status is also supported through hostel practice, which encourages sex offenders to see 
themselves as primarily that: a sex offender. For example, staff in the hostel always used residents' index offence as their primary identifier in formal and informal talk and in official paperwork, resulting in staff continually interpreting the behaviour of residents through the lens of, for example, 'sex offender', 'drug offender', 'rapist' or 'burglar' as appropriate, and reacting accordingly. Thus, as far as staff were concerned the resident was the offence, and the offence the resident.

"I wasn't prepared for how narrow-minded people would be here - residents and staff - they can't see you for you. Your offences are in the past....sex offenders may not do it again, they can't see that." (Paul in interview, younger resident convicted of sexual offences against children).

Similar attitudes in other criminal justice settings were found by Collins and Nee (2010: 324) who similarly argued that prison therapists' view of sex offenders as "manipulative, devious individuals, who were unlikely to be able to change their deviant sexual interests." negatively impacted on sex offenders' potential to positively change through the treatment process.

\section{The importance of grouping}

Group membership conveyed more than simply a network of social contacts, it also served to practically and emotionally support members and help them cope with the challenges of hostel life. Recently, some areas of work with sex offenders, notably COSA, have recognised this human need for socially supportive networks; endeavouring to use it to support relapse prevention and reintegration. Evaluations of the success of these measures are still in their infancy, but indicate a positive direction in sex offender management (Hanvey et al., 2011). COSA in particular are based on the knowledge that sex offenders are likely to be socially isolated and excluded within communities, thus increasing the likelihood of reoffending, but 
are positively affected by being part of pro-social, supportive and friendly networks. The need to be part of a social group is what drove sex offenders to group together in the hostel; they accepted each other and were supportive in times of stress. Although this was the foremost reason why residents associated with each other, it is necessary to consider the potential negative effects of membership of the sex offender group on individual's understandings of themselves.

It could be observed that from entering the hostel individuals underwent a process whereby they gradually explicitly expressed the dominant views and attitudes of the sex offender group as a whole: a process through which the group came to construct and share a group narrative and identity. This identity may vary from one group of sex offenders to the next, but in this study it served to encourage members to resist the rehabilitative and reintegration work undertaken with them. Infrequently some members of the sex offender group were able to reflect upon this process, and acknowledged the strength of the insidious and pervasive influence of grouping. In this quote Pete and Jim (older residents convicted of sexual offences against children) discussed the negative effects of forcing sex offenders to associate with one another within SOGP, again evidencing the importance of hostel structures and probation practice on social group identity:

Pete: I just think that the psychologists can get it wrong though. I mean, they could have one person sat there; first time offender, upset at what he's done. And another; repeat offender whose been through the system so many times. The course don't work on them, but they know what they should say, they know what people want them to say, and they say it. But then the psychologists say they are working well, but they might not be so positive about the first time offender who is genuine, but not saying the right things.

Jim: And there are plenty in there. The thing is you listen to these men, they've been offending for years; ... what do you call it...justifying it to themselves over all this time. Maybe not to themselves because they either really don't believe it's wrong or they don't care, but to others. And they are 
much more convincing then the psychologists who are just talking from a book. I don't mean that $I$ have been convinced, but they sound more convincing. And they are there all the time, not just once a week or whatever. (Pete and Jim, both older residents convicted of child sexual abuse offences, in interview.)

\section{Conclusion}

The study reported here was undertaken within one Probation Approved Premises in England and Wales, which had its own unique history, characteristics, staff and residents, and, thus, cannot be generalised to, or representative of, other criminal justice institutions. However, a single in-depth case study enabled the detail and multiplicity of the informal structures of social life within the resident population to be observed and the findings explored here may be used to consider similar resident or client groups within similarly closed and controlled institutions. Significantly, the findings here support and extend other studies, suggesting that sex offender groups are influential in group members' attitudes and behaviours, although the direction of this influence may differ according to the social situation of the group or the degree of input from probation officers or treatment facilitators. In particular, this paper suggests that the informal and largely unexplored social groupings of sex offenders can be a more powerful influence on individuals' engagement with criminal justice processes than the more transitory probation officers and facilitators of offence-based programmes they attend.

The findings also reflect theoretical work which notes the essentialised construct of the sex offender character; the current findings uncovering the manner in which other residents and hostel staff use and support this construction in their daily lives and working practice, but undermines the rehabilitative and reintegrative work of the hostel. In essence, each sex offender resident embodied the conflict between discourses and processes acting upon their moral and social being and defining their social and personal character and identity. The work undertaken in the hostel tended to demonize, exclude and isolate sex offender residents 
by subjecting them to structural and cultural processes and pressures which supported group formation and identity whilst emphasising the dominant discourse of sex offender as demonized other. These processes included not only practices of accommodating sex offenders together, and managing them as a group (for example, in SOG/TP), but also in the working practices and talk of staff. As a result of these pressures members of the sex offender group were placed in a social structure in which: a) they needed to form supportive social bonds to cope with the emotional, psychological and practical challenges presented by hostel life; b) they had little choice but to associate mainly or only with other sex offenders and c) they were encouraged to think of themselves in negative and essentialist terms. Thus, although sex offender grouping tends to be constructed in terms of increased risk through offender networking, they are structurally and culturally constrained in their social choices and moral understandings of their self.

\section{Implications}

That hostel practice underpinning work with sex offenders was found to reflect prevailing social discourses of demonization and difference (construing them in essentialist terms of the pathological individual, who may be controlled, constrained or managed, but never 'normal') conflicts with wider criminal justice discourses in (particularly) probation practice with nonsex offenders: that of promoting positive change, rehabilitation and reintegration. It is, therefore, important that future research explore the attitudes of staff working directly with sex offenders to determine how they conceptualise sex offenders and how this may affect their practice. In parallel, it is also essential to explore the narratives that sex offenders construct about themselves and their social relationships. In addition, research is required into how these groups form, whether it varies in more open or closed conditions, or institutions with greater or less local community contact. The knowledge gained from such exploratory 
studies can be utilised to design plans to manage the grouping process and effects as part of holistic risk management and effective reintegration as well as to question the policy of accommodating sex offenders together within criminal justice institutions.

More immediate practice implications centre on the need for all hostel workers to recognise the significance of the group structures and their function in supporting members' resistance to probation work. In particular, staff should understand that their own practice, talk and behaviours towards residents may reinforce group identities. However, it should be remembered that although mechanisms should be designed to reduce the negative influences of offence-based social groups in prisons and hostels, offenders still need socially supportive networks at this very challenging transitional point of their lives. Rather than remove these, positive alternative social networks should be presented. Simply distributing sex offenders more thinly amongst other offenders (so that they find it more difficult to group) is unlikely to be successful as they are likely to be at greater risk of harm, social exclusion and negative mood states, which are detrimental to preventing reoffending. However, the example of COSA on re-entering the community may be one mechanism that could be introduced to institutional settings to provide positive pro-social support that works with rather than against probation risk management. 


\section{References}

Atkinson. R., Flint, J. and Blandy, S. (2005), Toward a National Accommodation Strategy for Sex Offenders. Chartered Institute of Housing in Scotland, Scottish Executive.

Baldry, E., McDowell, D., Maplestone, P. and Peeters, M. (2002), 'Ex-prisoners and Accommodation: What bearing do different forms of housing have on social reintegration of ex-prisoners?' presented at the Housing, Crime and Stronger Communities Conference. Melbourne: Australian Housing and Urban Research Institute.

Brown, S. (2005), Treating Sex Offenders: An introduction to sex offender treatment programmes. Cullompton: Willan.

Brown, A. and Clough, R. [eds] (1989), Groups and Groupings: Life and work in day and residential centres. London: Routledge.

Buunk, B. P. (1996), 'Affiliation, Attraction and Close Relationships.' In Hewstone, M., Stroebe, W. and Stephenson, G. M. [eds] Introduction to Social Psychology $2^{\text {nd }}$ edition. Oxford: Blackwell.

Collins, S. and Nee, C. (2010), 'Factors influencing the process of change in sex offender interventions: Therapists experiences and perceptions.' Journal of Sexual Aggression: An international, interdisciplinary forum for research, theory and practice. 16 (3): 311-331. 
Ferrell, J. (1998), 'Criminological Verstehen: inside the immediacy of crime.' In Ferrell, J. and Hamm, M.S. [eds] (1998). Ethnography at the Edge: crime, deviance and field research. Boston: Northeastern University Press.

Fetterman, D.M. (1998), Ethnography: step by step. $\left[2^{\text {nd }}\right.$ ed]. London: Sage.

Hansard (2004), Sex Offenders (Hostel Accommodation). HC Deb 18 May 2004, 421 cc193$201 \mathrm{WH}$.

Hanvey, S., Philpot, T. and Wilson, C. (2011), A Community-Based Approach to the Reduction of Sexual Reoffending: Circles of Support and Accountability. London: JKP.

Haslam, S.A., O’Brien, A., Jetten, J., Vormedal, K. and Penna, S. (2005), 'Taking the Strain: social identity, social support and the experience of stress.' British Journal of Social Psychology. 44: 355-370.

HMI Probation (1998), Exercising Constant Vigilance: The Role of the Probation Service in Protecting the Public from Sex Offenders. London: Home Office.

HMI Probation, HMI Prisons and HMI Constabulary (2008), Probation Hostels: control, help and change? A Joint Inspection of Probation Approved Premises. London: Criminal Justice Joint Inspection. 
Hudson, K. (2005), Offending Identities: Sex Offenders' Perspectives on their Treatment and Management. Cullompton: Willan.

Kenemore, T.K. and Roldan, I. (2006), 'Staying Straight: lessons from ex-offenders." Clinical Social Work Journal. 34 (1): 5-21.

Krumer-Nevo, M. and Benjamin, O. (2010). 'Critical Poverty Knowledge: contesting othering and social distancing.' Current Sociology. 58: 693-714.

Lacombe, D. (2008), 'Consumed with Sex: the treatment of sex offenders in risk society.' British Journal of Criminology. 48: 55-74.

Laws, D. R. and Ward, T. (2011), Desistance from Sex Offending: Alternatives to throwing away the keys. London: Guilford Press.

Maruna, S. (2001), Making Good: how ex-convicts reform and rebuild their lives. Washington D.C.: American Psychological Association.

McPherson, M., Smith-Lovin, L. and Cook, J.M. (2001), 'Birds of a Feather: Homophily in social networks.' Annual Review of Sociology. 27: 415-44.

Ministry of Justice (2007), National Standards for the Management of Offenders. London: Ministry of Justice. 
NAPO and NPS (2009), Approved Premises Handbook 2009. London: Ministry of Justice, NOMS.

NAPO (2011), Written Evidence from NAPO (PB 05). London: House of Commons, Justice Committee.

National Probation Directorate (2005), The Role and Purpose of Approved Premises. Probation Circular 37/2005. London: NPD.

NPS (2004). Sex Offender Strategy for the National Probation Service. NPD, London.

Ost, S. (2009), Child Pornography and Sexual Grooming: legal and societal responses. Cambridge: Cambridge University Press.

Presser, L. (2009), 'The Narratives of Offenders.' Theoretical Criminology. 13: 177-200.

Scottish Executive (2003), Criminal Justice Accommodation Services: a review and consultation paper. Scottish Executive.

Ward, T., Polaschek, D.L.L. and Beech, A.R. (2006), Theories of Sexual Offending. Chichester: John Wiley and Sons Ltd.

Wincup, E. (2003), Residential Work with Offenders: reflexive accounts of practice. Aldershot: Ashgate. 
Young, J. (2007), The Vertigo of Late Modernity. London: Sage.

Young, J. (1999), The Exclusive Society: social exclusion, crime and difference in Late Modernity. London: Sage.

\footnotetext{
' Circles of Support and Accountability (COSA) are managed and formally accredited through the charity Circles UK, with the charity and the individual circles working in tandem with the National Offender Management Service, and the probation service in particular, to support the safe reintegration of high risk sex offenders being released from prison with limited or no supportive social networks. Based on the Canadian Community Reintegration Project, developed by the Mennonite church in 1994, the Quaker church in England and Wales championed and organised individually operating COSA prior to the establishment of Circles UK to oversee this process and national roll-out of the system. The approach embodied within COSA is based on pro-social group support and restorative justice (eschewing the cognitive behavioural therapy approach dominant in probation work) provided by a 'circle' of 4 to 6 trained volunteers supporting the offender in negotiating their re-entry into community life but who also challenge any risky behaviours and attitudes presented by the core circle member (the offender). Success of the circle is not only measured in terms of long-term safe reintegration, in which the offender constructs a positive social identity without re-offending, but also in terms of recall or other relapse prevention interventions based on the observations of circle members, without which reoffending would have been likely. For further information on the operation, work and evaluation of COSA see Hanvey et al. (2011).
}

ii MAPPPs and MARACs are part of the Home Office initiative of MAPPA (Multi-Agency Public Protection Arrangements) established through the Criminal Justice and Court Services' Act 2000, which came into effect in 2001. They are multi-agency committees involving members from a range of statutory and independent sectors that meet regularly to discuss local high risk offenders and develop plans to manage the risks of harm presented by them. In the Probation Area studied, MAPPPs were irregular meetings scheduled as needed to discuss individual very high and critical risk offenders who required immediate action from a range of agencies. MARACs were monthly meetings to discuss all level 2 and 3 MAPPA cases (normally medium high to high risk offenders requiring the involvement of two or more agencies to manage the risks they present). The cases discussed included sex offenders, violent and drug-related offenders. The Probation Area was separated into three MAPPP/MARAC panels based on geography to make the case load easier to manage. One of these MAPPP/MARAC panels was held in the hostel, and this is the one which the author was permitted access. For further information please see [reference to insert after anonympus review]. 